\title{
Effects of vildagliptin relative to sulfonylureas in Muslim patients with type 2 diabetes fasting during Ramadan: influence of age and treatment with/without metformin in the VIRTUE study
}

This article was published in the following Dove Press journal: Diabetes, Metabolic Syndrome and Obesity:Targets and Therapy 26 July 2016

Number of times this article has been viewed

\author{
Ahmed AK Hassoun' \\ Md Faruque Pathan ${ }^{2}$ \\ Rita C Medlej $j^{3,4}$ \\ Monira Alarouj ${ }^{5}$ \\ Inass Shaltout ${ }^{6}$ \\ Manoj S Chawla ${ }^{7}$ \\ Ditte Knap ${ }^{8}$ \\ Julius A Vaz \\ 'Dubai Diabetes Centre, Dubai, \\ UAE; ${ }^{2}$ Department of Endocrinology, \\ BIRDEM Hospital, Dhaka, Bangladesh; \\ ${ }^{3}$ Department of Endocrinology, Hotel \\ Dieu de France Hospital, ${ }^{4}$ Chronic \\ Care Centre, Saint Joseph University, \\ Beirut, Lebanon; ${ }^{5}$ Dasman Diabetes \\ Institute, Dasman, Kuwait; ${ }^{6}$ Faculty \\ of Medicine, Cairo University, \\ Cairo, Egypt; ${ }^{7}$ Lina Diabetes Care \\ Centre, Mumbai, India; ${ }^{8}$ Novartis \\ Pharma AG, Basel, Switzerland; \\ ${ }^{9}$ Novartis Healthcare Private Limited, \\ Hyderabad, India
}

Background: VIRTUE was a prospective, observational study assessing the effectiveness and safety of vildagliptin vs sulfonylureas (SUs) (both as monotherapy and in combination with metformin) in patients with type 2 diabetes mellitus who fasted during Ramadan. A post hoc analysis was carried out to assess the effect of treatment with/without metformin and age ( $<65$ years or $\geq 65$ years).

Patients and methods: Patients were recruited from the Middle East and Asia. The primary end point was proportion of patients with one or more hypoglycemic event (HE) during Ramadan. Secondary end points included change from baseline in glycated hemoglobin (HbA1c), body weight, and safety.

Results: Overall, 684 patients received vildagliptin and 631 received SUs. Most patients received dual therapy with metformin $(n=1,148)$ and were aged $<65$ years $(n=1,189)$. A few patients experienced one or more HE with vildagliptin vs SU monotherapy (6.5\% vs $14.5 \%)$ and with vildagliptin + metformin vs SUs + metformin (5.3\% vs $20.6 \%)$; the latter achieved statistical significance $(P<0.001)$ in both age subgroups ( $<65$ years: $5.5 \%$ vs $18.4 \%, P<0.001 ; \geq 65$ years: $2.8 \%$ vs $30.9 \%, P<0.001)$. Vildagliptin was associated with numerically greater HbA1c and body weight reductions vs SUs, regardless of the therapy type or age. A higher proportion of SU- vs vildagliptin-treated patients experienced adverse events across all subgroups.

Conclusion: A few patients experienced HEs with vildagliptin vs SUs regardless of age, and in patients on dual therapy. Vildagliptin \pm metformin was also associated with good glycemic and weight control and was well tolerated. Vildagliptin might be a useful treatment option for patients with type 2 diabetes mellitus, particularly high-risk populations such as the elderly fasting during Ramadan.

Keywords: age, metformin, Ramadan, sulfonylurea, type 2 diabetes, vildagliptin

\section{Introduction}

Despite discouragement from the medical community, $>50$ million Muslim individuals with type 2 diabetes mellitus (T2DM) fast during the holy month of Ramadan each year, abstaining from food, water, and the use of oral medications between dawn and sunset. ${ }^{1}$ Without relevant medical advice and intervention, fasting can put patients with T2DM at an increased risk of serious complications, including hypoglycemia, a result of missed and irregular meals together with the use of antidiabetic medication. ${ }^{1-3}$ Indeed, the EPIDIAR study that involved 11,173 patients with T2DM reported a significant 7.5-fold increase in the risk of severe hypoglycemia during Ramadan, compared with
Correspondence: Ahmed AK Hassoun Dubai Diabetes Center, Al Hudaiba Awards Buildings, Near the Union House, Southern end of 2 nd of December Street,Block C, First Floor, Dubai, PO Box 213480 , UAE

$\mathrm{Tel}+97 \mid 438196012$

Fax +97| 43546669

Email AAHassoun@dha.gov.ae
Diabetes, Metabolic Syndrome and Obesity:Targets and Therapy 2016:9 225-23I

225

Dovepress

http://dx.doi.org/10.2147/DMSO.S103692

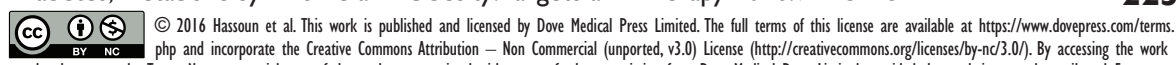
you hereby accept the Terms. Non-commercial uses of the work are permitted without any further permission from Dove Medical Press Limited, provided the work is properly attributed. For you hereby accept the Terms. Non-commercial uses of the work are permitted without any further permission from Dove Medical P
permission for commercial use of this work, please see paragraphs 4.2 and 5 of our Terms (https://www.dovepress.com/terms.php). 
previous months. ${ }^{1,3}$ Consequences of severe hypoglycemia can include cardiovascular complications, dementia, and death. ${ }^{4,5}$ Age itself is associated with an increased risk of hypoglycemic events (HEs), ${ }^{2,4}$ and elderly patients with T2DM are at a greater risk of developing serious complications from hypoglycemia. ${ }^{2,4-6}$ In fact, elderly patients with ill health have been identified as a high-risk population requiring careful management during fasting. ${ }^{1}$

Antidiabetic medication - particularly agents that increase insulin secretion independent of blood glucose - is a main cause of hypoglycemia in the nonfasting population with T2DM. ${ }^{2,4}$ A consensus document that outlines best practices for the management of patients with diabetes fasting during Ramadan advocates the use of antidiabetic agents that act by increasing insulin sensitivity rather than insulin secretion, thereby lowering the risk of hypoglycemia. ${ }^{1}$ For example, caution is advised for fasting patients receiving treatment with sulfonylureas $(\mathrm{SUs})^{1}$ because they increase insulin independent of blood glucose levels and are associated with a higher risk of HEs compared with other antidiabetic drugs. ${ }^{4}$ Furthermore, adjustments to the timing and dosing of particular antidiabetic treatments, including metformin and SUs, are recommended for patients wishing to fast during Ramadan. ${ }^{1}$ Accordingly, agents that promote glucose-dependent insulin release and enhance peripheral insulin action represent valuable treatment options for T2DM, particularly during the Ramadan period. ${ }^{7}$

Dipeptidyl peptidase-4 (DPP-4) inhibitors modulate insulin and glucagon secretion in a glucose-dependent manner and are associated with a low risk of hypoglycemia, a finding consistently reported across different patient populations with T2DM. ${ }^{8-14}$ Unlike SUs, no specific adjustments to DPP-4 treatment regimens are recommended for fasting patients. ${ }^{1}$ Vildagliptin is a potent and selective DPP-4 inhibitor ${ }^{9}$ and is associated with a lower incidence of HEs in head-to-head clinical trials with SUs. ${ }^{11-14}$ Moreover, a lower incidence of HEs with vildagliptin and with other DPP-4 inhibitors relative to SUs has been reported in studies of Muslim patients with T2DM fasting during Ramadan. ${ }^{15-20}$ One such report was from the VIRTUE study, a prospective, observational trial conducted in $>1,300$ Muslim patients from Asia and the Middle East in a real-life setting. ${ }^{20}$

This article reports the results of a post hoc analysis of the VIRTUE study data, which assessed the effect of treatment type (monotherapy or dual therapy with metformin) and patient age ( $<65$ years or $\geq 65$ years) on the incidence of HEs and changes to glycated hemoglobin (HbA1c) and body weight with vildagliptin relative to SUs in patients with T2DM fasting during Ramadan, studied in routine clinical practice.

\section{Patients and methods Study design and patient population}

Details of the VIRTUE study design and key patient eligibility criteria have been reported previously. ${ }^{20}$ This was a multicenter, prospective, noninterventional study conducted in the Middle East and Asia, and only data originating from routine clinical practice were collected. The study included adult ( $\geq 18$ years) Muslim patients diagnosed with T2DM $\geq 12$ months before the start of Ramadan fasting who were receiving treatment with vildagliptin or SUs (as monotherapy or as add-on to metformin, as per routine care and according to locally approved prescribing information) for $\geq 4$ weeks and $<3$ years prior to the start of fasting. All patients had a baseline $\mathrm{HbA} 1 \mathrm{c} \leq 8.5 \%$ within 6 weeks of study entry and provided written informed consent to the collection and use of data. The key exclusion criteria included contraindication to the medications of interest and requirement of three or more oral antidiabetic therapies or insulin therapy at study entry. Data were recorded from two or more routine clinic visits during an observational period of $\sim 16$ weeks: up to 6 weeks prior to the start of fasting (baseline visit) and within 6 weeks after the end of the fasting period (final visit). Data were recorded from any additional patient visits occurring during the fasting period. Written informed consent for the collection and use of data was obtained from all participants and the study was performed in accordance with the Good Pharmacoepidemiological Practices, national requirements/ regulations and the ethical principles laid down in the Declaration of Helsinki. The study was approved by the ethics committee at each center.

\section{Assessments}

As detailed previously, ${ }^{20}$ the primary objective of the VIRTUE study was to assess the proportion of Muslim patients with one or more HEs during the fasting period receiving vildagliptin or SU alone (where approved) or combined with metformin. HEs were further defined as either grade 1 (mild), ie, any reported symptoms by the patient and/or any blood glucose measurement $<3.9 \mathrm{mmol} / \mathrm{L}(70 \mathrm{mg} /$ $\mathrm{dL}$ ), or grade 2 (severe), defined as requirement of thirdparty assistance. Secondary objectives included changes in $\mathrm{HbA} 1 \mathrm{c}$ and body weight from prefasting baseline and overall safety, as assessed by monitoring of adverse events (AEs). 


\section{Statistical analyses}

Data from studies conducted under one umbrella protocol were pooled for analysis from Bangladesh, Egypt, India, Indonesia, Kuwait, Lebanon, Oman, Pakistan, Saudi Arabia, and the UAE..$^{20}$ Post hoc analyses were performed by therapy type (monotherapy and dual therapy) and patient age ( $<65$ years and $\geq 65$ years) on the primary study variable of HE incidence in the vildagliptin vs SU cohorts. Statistical significance was assessed using a two-sided Fisher's exact test performed on data from patients who received at least one dose of the medication of interest at the beginning of Ramadan and had at least one efficacy assessment after the start of fasting (primary analysis set). All other assessments, except $\mathrm{HbA1c}$ (primary analysis set), were performed on the safety population, ie, all patients receiving at least one dose of the medication of interest at the beginning of Ramadan and having experienced at least one safety assessment.

\section{Results}

\section{Patient demographics and baseline characteristics}

Of the 1,413 patients enrolled in the study, 1,333 patients have been included in the pooled analysis. Evaluable data were available for 1,315 patients, 684 of whom received vildagliptin therapy and $631 \mathrm{SU}$ therapy. ${ }^{20}$ Overall, 1,288 patients completed the study $(\mathrm{n}=668[97.7 \%]$ in the vildagliptin cohort and $n=620$ [98.3\%] in the SU cohort). As described previously, ${ }^{20}$ participating patients were from the Middle East and Asia, with patient demographics and baseline characteristics generally similar for the two treatment cohorts $(58.7 \%$ male, mean age 49.6 years, mean body mass index $29.0 \mathrm{~kg} / \mathrm{m}^{2}$, and mean $\mathrm{HbA1c} 7.4 \%)$.

As shown in Table 1, at baseline, the majority of patients in the study were receiving dual therapy with metformin $(n=1,148)$ and were aged $<65$ years $(n=1,189)$. The key baseline characteristics were broadly similar between the treatment cohorts for each subgroup analyzed, except for a longer duration of T2DM in patients aged $\geq 65$ years compared with those aged $<65$ years $(7.8$ years vs 3.6 years overall, respectively). In addition, changes to diabetes medication in preparation for Ramadan were more common among patients treated with SUs compared with those treated with vildagliptin, both in the overall population, ${ }^{20}$ and across subgroups of therapy type and age (Table 1). Overall, the median daily dose of each treatment was the same at the beginning and end of Ramadan. ${ }^{20}$

\section{Frequency of HEs}

In the overall population, as previously reported, a significantly few patients experienced one or more HEs with vildagliptin treatment compared with SUs $(5.4 \%$ vs $19.8 \%$, respectively; $P<0.001) .{ }^{20}$ Similar results were obtained when the incidence of hypoglycemia was analyzed according to the therapy type, with a few patients experiencing one or more HEs when treated with vildagliptin vs SU monotherapy and when receiving treatment with vildagliptin plus metformin compared with SU plus metformin; the latter comparison achieved statistical significance $(P<0.001$; Figure 1A). Analysis by age also showed a statistically significant difference in the proportion of patients with one or more HEs in favor of vildagliptin

Table I Patient demographics and baseline characteristics by therapy type and age (safety set)

\begin{tabular}{|c|c|c|c|c|c|c|c|c|}
\hline \multirow[t]{2}{*}{$\overline{\text { Variables }}$} & \multicolumn{2}{|c|}{ Monotherapy } & \multicolumn{2}{|c|}{ Dual therapy ${ }^{\mathrm{a}}$} & \multicolumn{2}{|l|}{$<65$ years } & \multicolumn{2}{|l|}{$\geq 65$ years } \\
\hline & $\begin{array}{l}\text { Vildagliptin } \\
(n=62)\end{array}$ & $\begin{array}{l}\text { SU } \\
(n=83)\end{array}$ & $\begin{array}{l}\text { Vildagliptin } \\
(n=607)\end{array}$ & $\begin{array}{l}\text { SU } \\
(n=54 I)\end{array}$ & $\begin{array}{l}\text { Vildagliptin } \\
(n=633)\end{array}$ & $\begin{array}{l}\text { SU } \\
(n=556)\end{array}$ & $\begin{array}{l}\text { Vildagliptin } \\
(n=36)\end{array}$ & $\begin{array}{l}\text { SU } \\
(n=68)\end{array}$ \\
\hline Sex (male), n (\%) & $36(58.1)$ & $43(5 \mathrm{I} .8)$ & $350(57.7)$ & $330(61.0)$ & $367(58.0)$ & $335(60.3)$ & $19(52.8)$ & $38(55.9)$ \\
\hline \multicolumn{9}{|l|}{ Race, n (\%) } \\
\hline Caucasian & $20(32.3)$ & $2(2.4)$ & $185(30.5)$ & $179(33.1)$ & $182(28.8)$ & 140 (25.2) & 23 (63.9) & $4 I(60.3)$ \\
\hline Black & $0(0.0)$ & $2(2.4)$ & $8(1.3)$ & $4(0.7)$ & $8(1.3)$ & $5(0.9)$ & $0(0.0)$ & I (I.5) \\
\hline Asian & $31(50.0)$ & $40(48.2)$ & $258(42.5)$ & $246(45.5)$ & $279(44.1)$ & $271(48.7)$ & $10(27.8)$ & $15(22.1)$ \\
\hline Other & II (I7.7) & $39(47.0)$ & $156(25.7)$ & I I 2 (20.7) & 164 (25.9) & 140 (25.2) & $3(8.3)$ & II (I6.2) \\
\hline Weight (kg), mean (SD) & $74.6(16.8)$ & $77.7(17.9)$ & $82.9(15.4)$ & $79.3(16.1)$ & $82.4(15.7)$ & $79.3(16.4)$ & $77.7(15.0)$ & 77.1 (I5.8) \\
\hline BMI $\left(\mathrm{kg} / \mathrm{m}^{2}\right)$, mean $(\mathrm{SD})$ & $26.6(4.9)$ & $28.1(5.5)$ & $29.7(5.1)$ & $28.7(5.1)$ & $29.4(5.1)$ & $28.6(5.1)$ & $29.7(6.6)$ & $28.5(5.1)$ \\
\hline $\begin{array}{l}\text { T2DM duration (years), } \\
\text { mean (SD) }\end{array}$ & $2.9(2.3)$ & $4.3(3.7)$ & $3.5(3.3)$ & $4.5(4.3)$ & $3.3(3.0)$ & $3.9(3.2)$ & $5.9(5.2)$ & $8.7(8.0)$ \\
\hline HbAlc (\%), mean (SD) & $7.5(0.7)$ & $7.5(0.9)$ & $7.3(0.8)$ & $7.4(0.8)$ & $7.3(0.8)$ & $7.5(0.9)$ & $7.5(0.7)$ & $7.2(0.8)$ \\
\hline $\begin{array}{l}\text { Change to diabetes } \\
\text { medication }^{\mathrm{b}}, \mathrm{n}(\%)\end{array}$ & $0(0.0)$ & $7(8.4)$ & $66(10.9)$ & $119(22.0)$ & $65(10.3)$ & $|2|(2 \mid .8)$ & I (2.8) & $5(7.4)$ \\
\hline
\end{tabular}

Notes: aPlus metformin. 'For fasting during Ramadan.

Abbreviations: SU, sulfonylurea; BMI, body mass index; T2DM, type 2 diabetes; HbAlc, glycated hemoglobin; SD, standard deviation. 

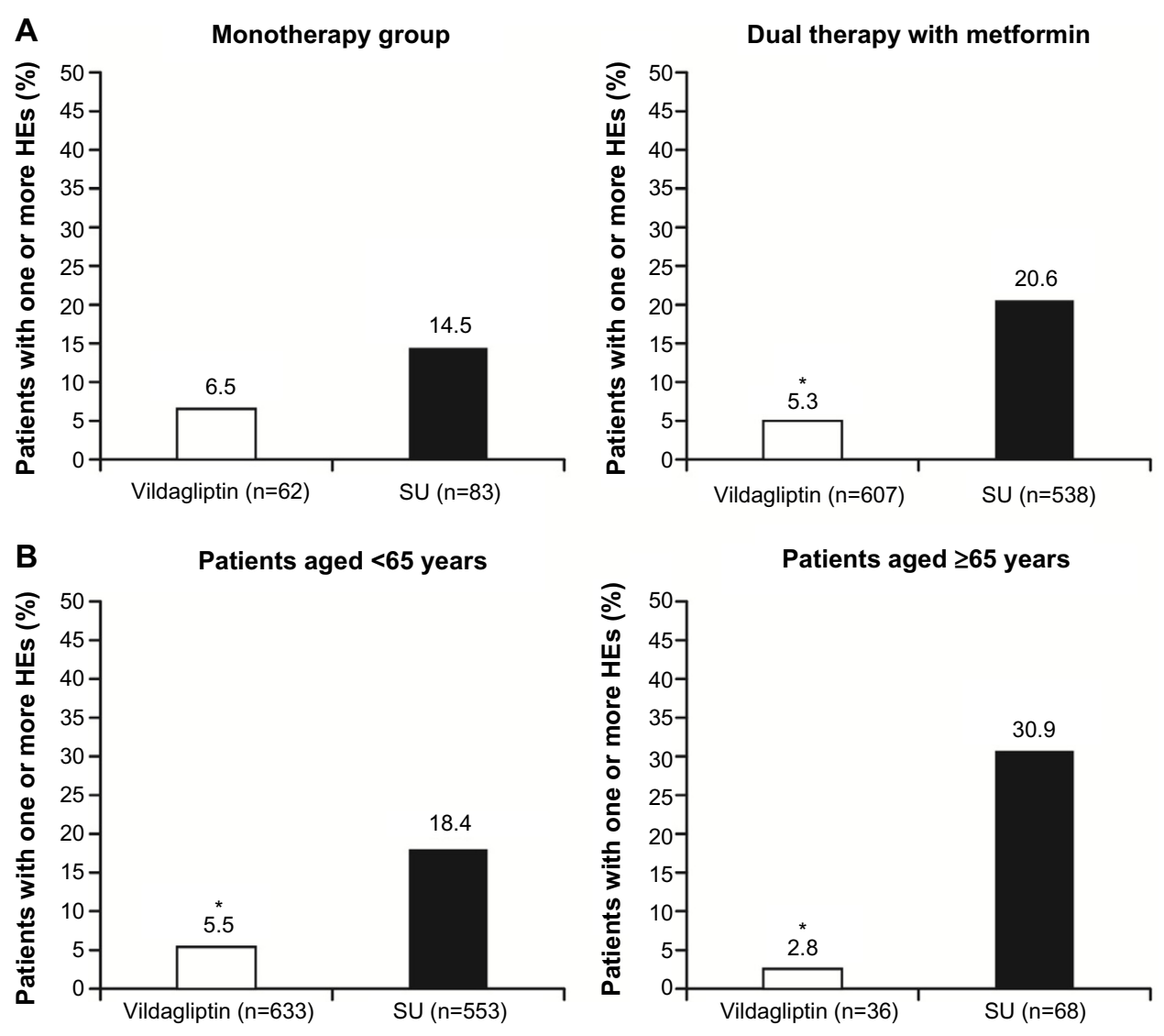

Figure I Number of patients in the vildagliptin and SU treatment cohorts with one or more HEs during Ramadan fasting according to (A) therapy type (monotherapy or dual therapy with metformin) and (B) age ( $<65$ years or $\geq 65$ years; primary analysis set).

Note: ${ }^{*} P<0.001$ vs SU cohort (Fisher's exact test).

Abbreviations: SU, sulfonylurea; HEs, hypoglycemic events.

compared with SU therapy $(P<0.001)$, with the treatment difference more pronounced in patients aged $\geq 65$ years (Figure 1B). No grade 2 (severe) HEs were reported by any patients treated with vildagliptin. In comparison, four $(0.7 \%)$ patients in the SU plus metformin group reported a grade $2 \mathrm{HE}$ ( $P=0.048$ vs vildagliptin dual therapy), of whom three were aged $<65$ years and one $\geq 65$ years. The majority of patients with hypoglycemia during fasting, whether analyzed by therapy type or by age, reported a single HE. In the monotherapy group, two (3.2\%) patients in the vildagliptin cohort and three (3.6\%) in the SU cohort experienced more than one HE. In the dual therapy groups, four $(0.7 \%)$ vildagliptin-treated and eleven $(2.0 \%) \mathrm{SU}$ treated patients reported more than one HE. No patient aged $\geq 65$ years experienced more than one HE in the vildagliptin cohort; one (1.5\%) patient aged $\geq 65$ years in the SU cohort experienced more than one HE. In the subgroup of patients aged $<65$ years, six $(0.9 \%)$ receiving vildagliptin and $13(2.3 \%)$ treated with SUs experienced more than one HE.

\section{$\mathrm{HbAlc}$ and body weight changes pre to post Ramadan}

Vildagliptin, as both monotherapy and dual therapy with metformin, was associated with a reduction in mean (SD) $\mathrm{HbA} \mathrm{c}$ from prefasting baseline levels to the end of the study $(-0.5 \%$ [0.4] and $-0.2 \%$ [0.6], respectively; Figure 2A). In comparison, mean (SD) $\mathrm{HbAlc}$ at the end of the study with SU monotherapy had increased slightly from baseline by $0.2 \%(0.8)$, and an insignificant change was observed following treatment with SU plus metformin $(0.0 \%$ [0.5]; Figure 2A). Vildagliptin treatment was also associated with numerically greater reductions in HbA1c compared with SU therapy in patients aged $<65$ years and in those aged $\geq 65$ years (Figure 2B). Mean changes in body weight pre to post Ramadan in the vildagliptin cohort compared with the SU cohort were $-0.31 \mathrm{~kg}$ vs $0.10 \mathrm{~kg}$, respectively, for patients in the monotherapy group and $-0.81 \mathrm{~kg} v \mathrm{v}-0.17 \mathrm{~kg}$, respectively, for patients in the dual therapy group. In the subgroup of patients aged $<65$ years, mean reductions in body weight from baseline were $-0.74 \mathrm{~kg}$ with vildagliptin and $-0.10 \mathrm{~kg}$ 

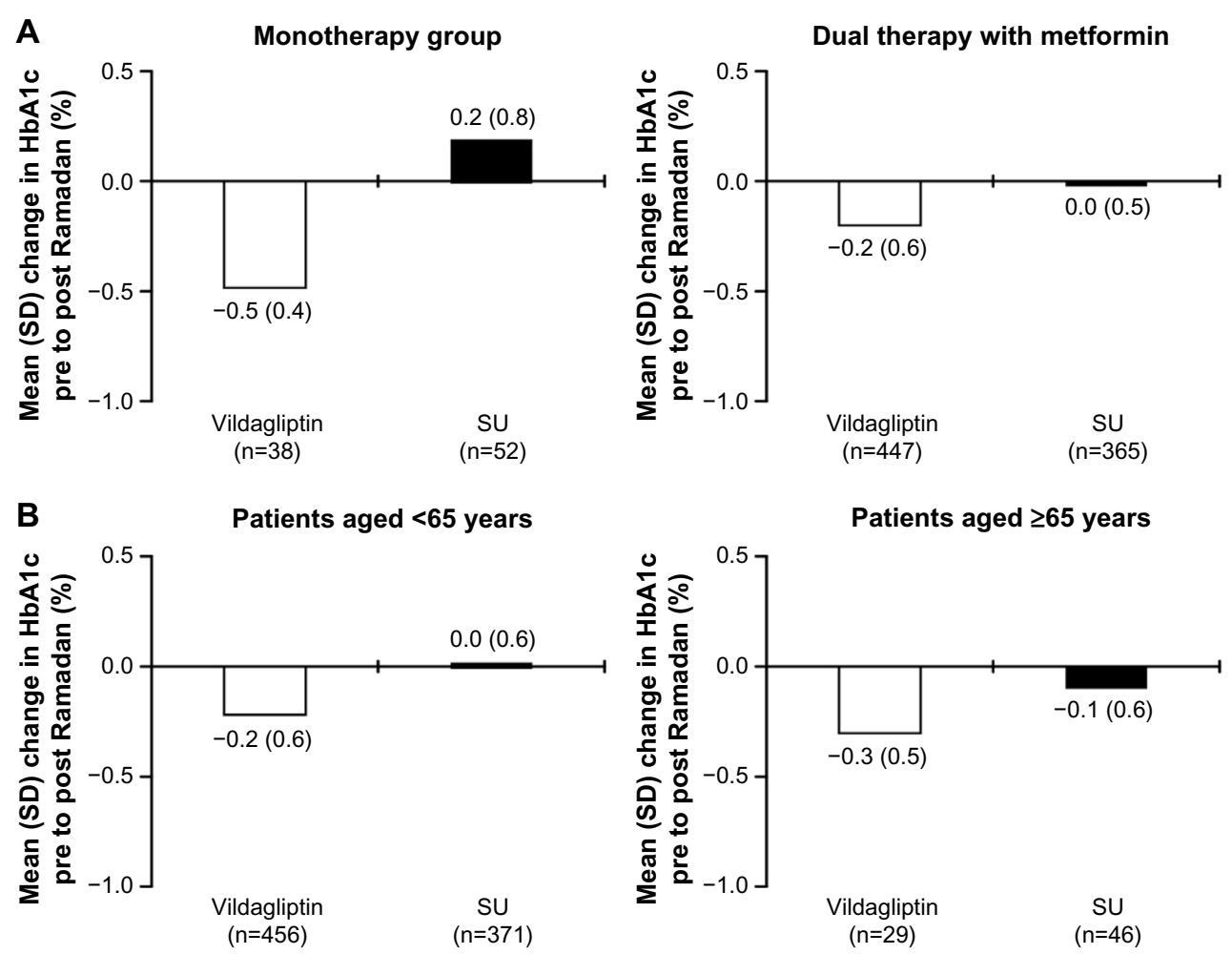

Figure 2 Mean (SD) change in $\mathrm{HbAlc}$ from prefasting baseline to study end for patients in vildagliptin and SU treatment cohorts. Notes: (A) Therapy type (monotherapy or dual therapy with metformin) and (B) age ( $<65$ years or $\geq 65$ years).

Abbreviations: HbAlc, glycated hemoglobin; SU, sulfonylurea; SD, standard deviation.

with SUs. Mean reductions in body weight from baseline in the subgroup of patients aged $\geq 65$ years were $-1.11 \mathrm{~kg}$ vs $-0.44 \mathrm{~kg}$ with vildagliptin and SU therapy, respectively.

\section{Safety and tolerability}

A higher proportion of patients treated with SUs experienced any AE compared with patients treated with vildagliptin, either as monotherapy (18.1\% vs $9.7 \%$, respectively) or in combination with metformin ( $23.5 \%$ vs $10.2 \%$, respectively). Similarly, a fewer patients experienced any AE when treated with vildagliptin compared with SUs in both age-groups ( $<65$ years: $10.6 \%$ vs $21.6 \%$, respectively; $\geq 65$ years: $2.8 \%$ vs $32.4 \%$, respectively). Differences observed in the incidence of AEs between the vildagliptin and SU cohorts were driven primarily by hypoglycemia, which was also the most common AE in both therapy and age subgroups. The other most frequently reported AEs were pyrexia (eight patients [1.3\%] in the vildagliptin group: one receiving monotherapy and seven dual therapy; eight patients $[1.4 \%]$ in the SU group: two receiving monotherapy and six dual therapy), nausea (six patients [0.9\%] in the vildagliptin group: all receiving dual therapy; two patients [0.4\%] in the SU group: both receiving dual therapy), vomiting (six patients $[0.9 \%$ in the vildagliptin group; one receiving monotherapy and five dual therapy; one patient $[0.2 \%]$ in the SU group receiving monotherapy), and diarrhea (five patients $[0.8 \%]$ in the vildagliptin group: all receiving dual therapy; two patients [0.4\%] in the SU group: both receiving dual therapy). All patients reporting these four specific AEs were aged $<65$ years.

In the vildagliptin plus metformin group, two $(0.3 \%)$ patients, both of whom were aged $<65$ years, experienced a serious AE (SAE) (myocardial infarction $[n=1]$ and viral hepatitis $[n=1])$. Five $(0.9 \%)$ patients experienced an SAE in the SU plus metformin group, four of whom were aged $<65$ years (hypoglycemia $[\mathrm{n}=3]$ and transient ischemic attack $[\mathrm{n}=1]$ ) and one aged $\geq 65$ years (hypoglycemia $[n=1]$ ). All nonhypoglycemic SAEs were considered to be unrelated to the study medication of interest. There were no reports of SAEs in patients receiving monotherapy with either vildagliptin or SUs.

\section{Discussion}

Findings from the VIRTUE study, conducted in a realworld setting in Muslim patients with T2DM fasting during Ramadan, indicated that treatment with the DPP-4 inhibitor vildagliptin was associated with a significant and clinically 
relevant reduction in the incidence of HEs compared with SU treatment. Notably, lower frequency of HEs was observed with vildagliptin independent of the type of SU employed. ${ }^{20}$ Although a lower frequency of HEs with DPP-4 treatment compared with SUs as monotherapy or as dual therapy with metformin during Ramadan has been reported by other studies conducted in patients with T2DM fasting during Ramadan, ${ }^{8,15-19}$ the current study extends this analysis to monotherapy or dual therapy type and age.

The majority of patients in our study received dual therapy with metformin, and the results demonstrated a significant, clinically relevant reduction in HE frequency during Ramadan in vildagliptin plus metformin-treated patients compared with those receiving SU plus metformin. Although a few patients experienced HEs with vildagliptin monotherapy relative to SU monotherapy, the between-treatment difference was not statistically significant when tested in this relatively small subgroup. A statistically significant lower incidence of HEs with vildagliptin in comparison to SUs was observed regardless of age, ie, <65 and $\geq 65$ years. While specific statistical comparisons between the age subgroups were not performed, the reduction in $\mathrm{HE}$ frequency in the vildagliptin- vs SU-treated cohort appeared to be amplified in those aged $\geq 65$ years. This finding is of clinical importance, given that elderly patients tend to be at a higher risk of developing hypoglycemia and are more likely to experience debilitating consequences from severe HEs. ${ }^{2,4-6}$ In this analysis by age, three patients aged $<65$ years and one patient aged $\geq 65$ years experienced a grade $2 \mathrm{HE}$ in the SU cohort. No severe grade 2 HEs were reported in patients receiving vildagliptin monotherapy or dual therapy compared with four severe HEs in the SU dual therapy group. Overall, these findings might be expected when considering the mechanistic action of SUs, which increase insulin independent of blood glucose levels, ${ }^{4}$ and given the higher risk of HEs with SUs compared with vildagliptin and other DPP-4 inhibitors reported in clinical trials. ${ }^{10-13}$ Vildagliptin is a DPP-4 inhibitor that improves glycemic control by modulating insulin and glucagon secretion in a glucose-dependent manner and is associated with low risk of hypoglycemia and weight gain in clinical trials. ${ }^{8-14}$

As observed in two other studies that assessed HbAlc pre and post Ramadan in vildagliptin and SU cohorts, ${ }^{16,21}$ a significant reduction in $\mathrm{HbA} 1 \mathrm{c}$ from baseline with vildagliptin compared with SU treatment was reported during Ramadan in the overall VIRTUE population. ${ }^{20} \mathrm{~A}$ trend indicating greater reductions in $\mathrm{HbA} 1 \mathrm{c}$ from prefasting baseline with vildagliptin relative to SU treatment during Ramadan was also observed in the monotherapy and dual therapy subgroups and in patients aged $<65$ years and $\geq 65$ years in the current analysis. This finding may partly be a result of patients avoiding higher doses of SUs or reducing their SU dosage in preparation for Ramadan fasting.

Changes in dietary patterns during Ramadan and the short study duration make it difficult to draw definitive conclusions from body weight changes in this analysis. Nevertheless, small reductions in body weight from prefasting baseline were reported in all therapy type and age subgroups of patients receiving vildagliptin, with a trend for numerically greater reductions in weight relative to SU treatment across all subgroups.

Vildagliptin monotherapy and dual therapy with metformin were generally well tolerated by fasting patients in the study. Similarly, vildagliptin therapy was also generally well tolerated regardless of age. Although the reliance on data collected by physicians in routine practice may have led to the underreporting of AEs and HEs, the trend for a lower AE frequency with vildagliptin relative to SU treatment observed for the overall study population ${ }^{20}$ was also reported in both monotherapy and dual therapy as well as age subgroups, and was driven primarily by hypoglycemia as the most common AE in all subgroups. This also appears to be in agreement with the trend for lower AE frequency with vildagliptin relative to $\mathrm{SU}$ treatment reported in other studies of patients fasting during Ramadan. ${ }^{8,15,16}$ The low frequency of AEs in patients aged $\geq 65$ years treated with vildagliptin (2.8\%) compared with SUs (32.4\%), which was driven by the difference in HEs, indicates that vildagliptin was particularly well tolerated in this vulnerable population.

Limitations of the VIRTUE study have been reported previously, ${ }^{20}$ but in brief relate mainly to the observational, nonrandomized nature of the study design and the absence of standardized methods for data collection, which together may potentially allow for observer bias. Despite the study design, however, it is worth noting that the large study population observed in this real-world setting increases the robustness of the results and improves generalizability to a broader population than could be achieved in a single randomized, interventional trial.

\section{Conclusion}

VIRTUE is the first Ramadan study conducted in fasting patients with T2DM in routine practice to provide data on the influence of therapy with or without metformin and age on vildagliptin and SU treatment effects. As oral agents that promote insulin and inhibit glucagon secretion in a glucosedependent manner, DPP-4 inhibitors, such as vildagliptin, are emerging as useful treatment options as monotherapy or in combination with metformin in patients with T2DM. Among the commonly used antidiabetic agents, the beneficial effects 
of vildagliptin on $\mathrm{HbA1c}$, hypoglycemia incidence, and weight make it a potential treatment of choice for fasting patients, particularly high-risk populations such as the elderly.

\section{Acknowledgments}

This study was funded by Novartis Pharma AG and its respective affiliates. The authors thank all investigators and subinvestigators. All authors participated in the development and writing of the manuscript and take full responsibility for the content of the article. The authors wish to thank Doctor Sashka Hristoskova and Doctor Mahomed Kadwa from Novartis Pharma AG for their critical reviews and suggestions to the manuscript. The authors were assisted in the preparation of this text by Isobel Lever and Sharon Smalley of CircleScience, Macclesfield, UK; this support was funded by Novartis Pharma AG. The authors thank Abhijit Shete (Novartis Pharma AG) and Abhilasha Verma (Novartis Healthcare Private Limited, Hyderabad, India) for technical assistance with the submission of the manuscript.

\section{Disclosure}

M Al-Arouj, AAK Hassoun, R Medlej, M Faruque Pathan, I Shaltout, and MS Chawla have received investigator fees related to the conduct of the VIRTUE study and have received consultancy fees for advisory/speaker engagements from Novartis and its affiliates. D Knap is an employee of Novartis Pharma AG. JA Vaz is an employee of Novartis Pharma AG and a shareholder of Novartis Healthcare Private Limited, Hyderabad, India. The authors report no other conflicts of interest in this work.

\section{References}

1. Al-Arouj M, Assaad-Khalil S, Buse J, et al. Recommendations for management of diabetes during Ramadan: update 2010. Diabetes Care. 2010;33(8):1895-1902.

2. Amiel SA, Dixon T, Mann R, Jameson K. Hypoglycaemia in type 2 diabetes. Diabet Med. 2008;25(3):245-254.

3. Salti I, Bénard E, Detournay B, et al; EPIDIAR study group. A population-based study of diabetes and its characteristics during the fasting month of Ramadan in 13 countries: results of the epidemiology of diabetes and Ramadan 1422/2001 (EPIDIAR) study. Diabetes Care. 2004;27(10):2306-2311.

4. Barnett AH. Avoiding hypoglycaemia while achieving good glycaemic control in type 2 diabetes through optimal use of oral agent therapy. Curr Med Res Opin. 2010;26(6):1333-1342.
5. Whitmer RA, Karter AJ, Yaffe K, Quesenberry CP, Selby JV. Hypoglycemic episodes and risk of dementia in older patients with Type 2 diabetes mellitus. JAMA. 2009;301(15):1565-1572.

6. Kirkman MS, Briscoe VJ, Clark N, et al. Diabetes in older adults. Diabetes Care. 2012;35(12):2650-2664.

7. Ibrahim M, Abu Al Magd M, Annabi FA, et al. Recommendations for management of diabetes during Ramadan: update 2015. BMJ Open Diabetes Res Care. 2015;3(1):e000108.

8. Schweizer A, Halimi S, Dejager S. Experience with DPP-4 inhibitors in the management of patients with type 2 diabetes fasting during Ramadan. Vasc Health Risk Manag. 2014;10:15-24.

9. Keating GM. Vildagliptin: a review of its use in type 2 diabetes mellitus. Drugs. 2010;70(16):2089-2112.

10. Schweizer A, Dejager S, Foley JE, Shao Q, Kothny W. Clinical experience with vildagliptin in the management of type 2 diabetes in a patient population $\geq 75$ years: a pooled analysis from a database of clinical trials. Diabetes Obes Metab. 2011;13(1):55-64.

11. Matthews DR, Dejager S, Ahren B, et al. Vildagliptin add-on to metformin produces similar efficacy and reduced hypoglycaemic risk compared with glimepiride, with no weight gain: results from a 2-year study. Diabetes Obes Metab. 2010;12(9):780-789.

12. Ferrannini E, Fonseca V, Zinman B, et al. Fifty-two-week efficacy and safety of vildagliptin vs glimepiride in patients with type 2 diabetes mellitus inadequately controlled on metformin monotherapy. Diabetes Obesity Metab. 2009;11(2):157-166.

13. Sheen AJ. DPP-4 inhibitors in the management of type 2 diabetes: a critical review of head-to-head trials. Diabetes Metab. 2012;38(2):89-101.

14. Sheen AJ, Paquot N. Gliptin versus a sulfonylurea as add-on to metformin. Lancet. 2012;380(9840):450-452.

15. Halimi S, Levy M, Huet D, Quere S, Dejager S. Experience with vildagliptin in type 2 diabetic patients fasting during ramadan in France: insights from the VERDI study. Diabetes Ther. 2013;4(2): 385-398.

16. Hassanein M, Hanif W, Malik W, et al. Comparison of the dipeptidyl peptidase-4 inhibitor vildagliptin and the sulfonylurea gliclazide in combination with metformin, in Muslim patients with type 2 diabetes mellitus fasting during Ramadan: results of the VECTOR study. Curr Med Res Opin. 2011;27(7):1367-1374.

17. Devendra D, Gohel B, Bravis V, et al. Vildagliptin therapy and hypoglycaemia in Muslim type 2 diabetes patients during Ramadan. Int J Clin Pract. 2009;63(10):1446-1450.

18. Al Sifri S, Basiounny A, Echtay A, et al; 2010 Ramadan Study Group. The incidence of hypoglycaemia in Muslim patients with type 2 diabetes treated with sitagliptin or a sulfonylurea during Ramadan: a randomised trial. Int J Clin Pract. 2011;65(11):1132-1140.

19. Aravind SR, Al Tayeb K, Ismail SB, et al; 2009 Ramadan Study Group. Hypoglycaemia in sulfonylurea-treated subjects with type 2 diabetes undergoing Ramadan fasting: a five-country observational study. Curr Med Res Opin. 2011;27(6):1237-1242.

20. Al-Arouj M, Hassoun AA, Medlej R, et al. The effect of vildagliptin relative to sulfonylureas in Muslim patients with type 2 diabetes fasting during Ramadan: the VIRTUE study. Int J Clin Pract. 2013;67(10): 957-963.

21. Shete A, Shaikh A, Nayeem KJ, et al. Vildagliptin vs sulfonylurea in Indian Muslim diabetes patients fasting during Ramadan. World $J$ Diabetes. 2013;4(6):358-364.

Diabetes, Metabolic Syndrome and Obesity: Targets and Therapy

\section{Publish your work in this journal}

Diabetes, Metabolic Syndrome and Obesity: Targets and Therapy is an international, peer-reviewed open-access journal committed to the rapid publication of the latest laboratory and clinical findings in the fields of diabetes, metabolic syndrome and obesity research. Original research, review, case reports, hypothesis formation, expert
Dovepress

opinion and commentaries are all considered for publication. The manuscript management system is completely online and includes a very quick and fair peer-review system, which is all easy to use. Visit $\mathrm{http}: / /$ www.dovepress.com/testimonials.php to read real quotes from published authors. 